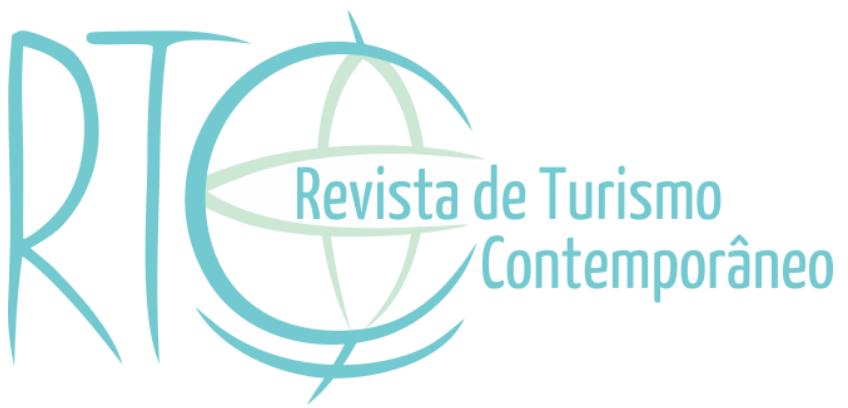

\title{
Agroturismo: cultura e identidade agregando renda no espaço rural
}

\section{Agritourism: culture and gender identidy adding income in rural area}

Beatriz Mauro Zandonadi

Professora da Rede Estadual de Ensino-SEDU. Vitória /ES, Brasil

E-mail: biazandonadi@yahoo.com.br

Ana Lucy Oliveira Freire

Professora Associada da Universidade Federal do Espirito Santo-UFES. Vitória/ES, Brasil E-mail: alucy.freire@gmail.com

Artigo recebido em: 01-08-2015

Artigo aprovado em: 24-05-2016 


\section{RESUMO}

O espaço rural brasileiro vem passando por mudanças importantes nas últimas três décadas. Novas atividades econômicas se destacam num cenário que gera transformações sociais e culturais sobre a realidade rural do país, incluso nesse quadro o município de Venda Nova do Imigrante (ES), objeto deste estudo. Localizado na região centro serrana, dotado de clima ameno, relevo pontuado de serras, tem forte influência dos imigrantes italianos que colonizaram a região, além de uma economia baseada na agricultura, o município vem ganhando notoriedade numa nova atividade: o agroturismo. $\mathrm{O}$ agroturismo vem se mostrando uma maneira de recuperar e ressaltar os traços culturais típicos; manter a identidade tradicional dos produtores; dinamizar o espaço local; sendo ainda uma forma de inserir os ganhos com as novas atividades na economia urbana. Com base em revisões bibliográficas teóricas, em pesquisas primárias sobre o tema local e em trabalhos de campo, esse artigo objetiva discutir e analisar as novas atividades ligadas ao agroturismo, assim como estas podem contribuir no desenvolvimento da economia rural, mantendo e reativando conhecimentos e heranças culturais que ajudam na manutenção da identidade dos produtores locais. Pretende também pontuar alguns cuidados a serem tomados para que tais atividades turísticas não percam seu propósito principal.

Palavras-chave: Identidade. Cultura. Vida Rural. Agroturismo.

\section{ABSTRACT}

The Brazilian countryside has passing for major changes over the past three decades. New economic activities include a scenario that generates social and cultural changes on the rural reality of the country, included in this framework the municipality of Venda Nova do Imigrante (ES), object of this study. Located in mountainous central region, endowed with a mild climate, relief punctuated by mountains, has a strong influence of Italian immigrants who settled the area in addition to an economy based on agriculture, the town has gained notoriety in recent activity: agritourism. The agritourism has proven to be a way to recover and emphasize the typical cultural traits; maintain the traditional identity of the producers; boost local space; still a way to insert the gains from the new activities in the urban economy. Based on theoretical literature reviews, in primary research on local theme and fieldwork, this article aims to discuss and analyze new activities related to agritourism, as these can contribute to the development of the rural economy, maintaining and reactivating knowledge and heritage cultural factors that help in maintaining the identity of local producers. Also aims to score some care should be taken that such tourist activities do not lose their main purpose.

Keywords: Identity. Culture. Country Life. Agritourism. 


\section{INTRODUÇÃO}

O rural e o urbano simbolizavam espaços opostos e essas diferenças eram bem marcadas. Um era o lócus das atividades agrícolas e agropecuárias, ligado a um tempo mais lento, às tradições e simbolizava o atraso, o não moderno. $\mathrm{O}$ outro, ao contrário, estava ligado às atividades produtivas dos setores secundários e terciários, com um tempo acelerado, e associado à modernidade. Hoje, com as novas atividades sendo desenvolvidas no meio rural a relação entre campo e cidade passam por mudanças, esses espaços passaram a ter um relacionamento mais estreito e as trocas não se dão apenas no sentido de o campo receber as novidades que vêm da cidade.

O espaço rural brasileiro que servia como base para as atividades agrícolas e agropecuárias, visto como fornecedor de matéria prima para a indústria, e classificado como atrasado em oposição à cidade vem passando por transformações significativas, as quais impõem mudanças na própria vida. Assim, algumas atividades realizadas a partir no espaço urbanoindustrial, tais como do setor secundário e terciário, passaram a ser realizadas também no espaço rural.

Dentre as novas atividades desenvolvidas no campo, as relacionadas ao turismo têm recebido destaque atualmente, isso porque se mostram como alternativas em gerar novas dinâmicas econômicas para áreas cujos setores tradicionais do campo entram em declínio conforme crises cíclicas do mercado.

Além de possibilitar novas formas de ganho econômico para as populações rurais, incentivam a preservação dos aspectos naturais, valorizam o campo e sua população, através da inserção num mercado que hoje passou a valorizar, como mercadoria, o que se costuma chamar de arcaico. Assim, há um processo de recuperação de técnicas tradicionais que, potencializadas pelas técnicas modernas de planejamento e organização advindos de ramos da ciência tais como administração e agronomia, por exemplo, vão transformando os símbolos tradicionais em mercadorias, além de ser uma maneira de manter a identidade cultural dos moradores do campo.

Nesse sentido, esse artigo, parte de uma pesquisa que resultou numa dissertação de mestrado, tem como objetivo geral entender como a atividade do agroturismo colabora na dinâmica econômica no município de Venda Nova do Imigrante (ES), salientando aspectos que demostram como o desenvolvimento do agroturismo pode ajudar na manutenção da identidade e da cultura dos produtores rurais locais, além de ser fonte de renda no meio rural. 
Metodologicamente, para a realização deste trabalho foram usadas revisões bibliográficas a respeito da temática principalmente em periódicos e livros. Foram usados dados do Instituto Brasileiro de Geografia e Estatística [IBGE], acerca da economia geral, informações fornecidas pelo Instituto Jones dos Santos Neves- ES [IJSN] e do Instituto de Defesa Agropecuária e Florestal do Espírito Santo [IDAF] e outras instituições públicas municipais, tais como secretarias de turismo, Serviço Brasileiro de Apoio a Micro e Pequenas Empresas [SEBRAE] local, Instituto Federal de Educação Superior [IFES] e Secretaria Municipal de Agricultura, material coletado presencialmente.

A operacionalização da pesquisa de campo se deu a partir da sistematização de trabalhos empíricos (entrevistas semiestruturadas e depoimentos livres realizadas pelas autoras) junto às propriedades rurais que praticam o agroturismo e fazem parte do circuito do agroturismo em Venda Nova do Imigrante. A partir do cadastro oficial do agroturismo no município, o qual conta com mais de 40 propriedades, optou-se por uma amostragem englobando um total de 17 num universo de 23 contidas no panfleto turístico local dos anos de 2013 e 2014, ou seja, $69,56 \%$ do total. A escolha destas propriedades levou em conta as práticas na produção de caráter familiar e preconizadas pelo agroturismo, o que não ocorre na maioria delas.

\section{ALGUMAS PALAVRAS SOBRE CULTURA}

Alguns esclarecimentos que se seguem são relevantes, posto que cultura é um termo bastante polissêmico e de difícil conceituação. Para fins de posicionamento neste trabalho, associa-se aqui a idéia de cultura a modo de vida, constituído de valores, ações, padrões de comportamento, elementos, características, manifestações, símbolos e significados dos ritmos, hábitos, rituais, costumes, tradições, etc., os quais são assimilados de modo natural e vão se reproduzindo ao longo da vida das pessoas, dos grupos e das comunidades. Ou seja, diz respeito a toda uma ordem simbólica que ajuda a (re)afirmar identidades; expressões dos modos como os homens vivem e formas como eles estabelecem relações entre si e com o mundo em seu entorno (Costa, 2005).

No que tange ao modo de vida, diríamos que um conjunto de valores caracteriza modos de viver enquanto culturas próprias, singulares, isto é, fonte de onde nasce o diferente, de onde minam os folclores; uma prática cultural apoiada em determinismos tradicionais, em elementos (da moradia, da alimentação, do jeito de se vestir, do modo de se comportar, das relações, do modo de produzir, dos saberes e fazeres, etc.) legados do passado, que se 
enraízam, se fortalecem, cria e reproduz identidades; dos saberes e fazeres que tem o seu valor no mundo contemporâneo.

No âmbito da discussão sobre a noção de cultura, é importante assinalar que houve uma espécie de evolução, assim como um desvio histórico do significado de tal termo. No final, o que se verifica, na atualidade, é que se generalizou a compreensão do seu sentido. Trata-se de que cultura, se o próprio capitalismo parece ter se tornado uma cultura - a sociedade capitalista enquanto cultura -, uma cultura calcada em muito na produção e no consumo como parte da lógica capitalista atual?

Discutir a noção de cultura significa, em primeiro lugar, pensar na modernidade, bastante expressa nas artes e nas descobertas técnicas. Processo que amadureceu com o capitalismo, se universalizou e se diluiu no século XIX. Depois de decorridos mais de um século, vivenciamos a era da modernização acelerada, marca de uma sociedade cambiante que demanda uma sociedade essencialmente urbana, mesmo vivendo, às vezes por modismos, no que se convém denominar rural.

A partir do século XIX, cultura passou a ser sinônimo de "civilização", em oposição às sociedades bárbaras, selvagens, não civilizadas. Segundo Thompson (1998, p. 169), discutindo o conceito de cultura e civilização, os usos destes termos se sobrepuseram: ambas foram, progressivamente, sendo usadas para descrever um processo geral de desenvolvimento humano, de se tornar "culto" ou "civilizado".

Para Cascudo (1973), cultura está associada a toda uma maneira de viver de uma sociedade, entendida também como um povo que tem um patrimônio construído de tradições, de costumes, normas, doutrinas, hábitos, técnicas herdadas e passadas para outras gerações.

Segundo Claval (2007, p. 163), a cultura é inerente aos seres humanos e está assentada numa base geográfica, que é o espaço. Sobre essa base, os homens em comunidade trabalham, se comunicam, observam e transformam o seu entorno, atribuem significados aos objetos, participam dos mesmos rituais, criam hábitos, recordam o passado, vivem uma cultura comum, e, porquê não dizer, um modo de vida. Para este autor "a cultura aparece como um conjunto de gestos, práticas, comportamentos, técnicas, know how, conhecimentos, regras, normas e valores herdados dos pais e da vizinhança, e adaptados através da experiência e realidades sempre mutáveis. A cultura é herança e experiência”.

Para a Geografia Cultural, focada no papel do homem transformador da face da Terra, cultura era entendida como um conjunto de práticas comuns compartilhadas em grupo, em particular, práticas que foram aprendidas e transmitidas através de gerações. Para Cosgrove (1998, p. 101), trata-se de determinismo cultural, uma vez que, conforme o mesmo diz, "a 
cultura não é algo que funciona através dos seres humanos; pelo contrário, tem que ser reproduzida por eles em suas ações, muitas das quais são ações não reflexivas, rotineiras da vida cotidiana (...) a cultura é, ao mesmo tempo, determinada por e determinante da consciência das práticas humanas".

\section{TURISMO E AGROTURISMO: A CULTURA E AS NOVAS POSSIBILIDADES ECONÔMICAS}

Por que o turismo é, hoje, um fenômeno? O turismo precisa ser predador, voraz no processo que consome os lugares como atrativos? O turismo faz parte de um modo ou estilo de vida hoje? Essas e outras questões recheiam o universo das dúvidas, dos argumentos, das discussões, dos discursos, das críticas, etc., os quais instigam a pesquisa que, por sua vez, pretendem chamar a atenção para essa prática e atividade atual mundial, a qual ganha cada vez mais evidência nos estudos de diversos campos do saber científico, sobretudo no âmbito das ciências humanas e sociais.

Quando se discute o nascimento ou a emergência do turismo, comumente faz-se uma articulação com a curiosidade, o interesse, o desejo do indivíduo em conhecer um lugar específico que o atrai, principalmente porque se trata de um lugar "diferente" daquele do seu cotidiano; surge como uma necessidade de fugir, de sair um pouco do dia-a-dia comum.

Comumente associa-se turismo cultural aos monumentos, aos bens materiais tombados, posto que fazem parte do patrimônio do país. (Pires, 2002). Contudo, faz-se necessário salientar que, no que tange ao presente estudo, a articulação entre turismo e cultura que se apresenta pensa nos saberes, fazeres e nas práticas vividas enquanto parte da cultura imaterial, o que não exclui a construção de espaços culturais.

No momento atual, ou pelo menos desde que o turismo transformou-se num filão econômico, assistimos mudanças na sua natureza. Os tempos em que o turismo significava a chegada das férias para viajar, descansar, conhecer novos lugares e pessoas, ou até mesmo para simplesmente visitar os parentes e amigos distantes, ficaram para trás. Em primeiro lugar porque, hoje, o turismo ocorre o tempo todo, isto é, no decorrer do ano (nas férias escolares, nos muitos feriados, nos fins de semana...); não se limita mais ao aproveitamento das clássicas férias de final de ano (Rodrigues, 1997).

Por seu caráter de liberdade, de ser livre para ocorrer em qualquer parte e em qualquer hora sem prévia autorização de ninguém (salvo em alguns casos do turismo planejado), o turismo, sobretudo as formas turísticas vorazes de destruição (em plena expansão), traz danos 
irreparáveis às sociedades, aos espaços, sejam eles locais, regionais, nacionais ou mundiais. Nesse sentido, pensar no turismo como um importante vetor de desenvolvimento carece pensar no planejamento, ou pelo menos em estratégias como "arma" para conter os dados negativos do turismo.

O turismo, em seus aspectos positivos e como prática e atividade econômica viável, em muitos casos, é visto hoje como uma esperança. Quando as possibilidades de exploração de algumas atividades já não são mais possíveis para uma área, uma cidade, uma região dotada de predicados que de algum modo podem ser aproveitados, eis que aparece aquela chance de ver esse lugar voltar a "ter vida", o que significa aproveitar certa área e transformála em atrativo turístico, como fonte de renda.

O turismo pode ser designado algo além de uma atividade econômica com grandes significados? Cremos que sim, posto que ele aflora revolucionando modos de vida, culturas, estilos de vida; é capaz de transformar um lugar, regiões, bairros e comunidades inteiras; é uma mercadoria especial e, portanto, é parte da sociedade de consumo que se constitui. É serviço (o terciário tradicional?); é uma indústria (a velha indústria?) - a indústria do turismo -, mas também uma prática social e um processo civilizatório (Rodrigues, 1997, p. 17).

Dado às muitas transformações tecnológicas dos últimos 30 anos, sobretudo nos meios de comunicação, mudando as relações espaço-tempo, os espaços passam a ser ligados por redes de fluxos de muita rapidez, o que, equivocadamente, dar a entender que o espaço seja eliminado (Santos, 1996). O turismo torna esse processo mais fácil, disseminando dados e informações, fazendo propaganda do lugar "descoberto", transformado em potencial atração turística.

Em Geografia, quando se pensa em lugar e seu significado associa-o a questão da escala, uma vez que local e lugar nos remete a ideia de pequeno: a localidade, a pequena cidade, o vilarejo, o bairro e a comunidade, até porque como analisa Santos (1996, p. 258), o lugar é também o teatro das manifestações de espontaneidade e de criatividade. O lugar tem a ver, portanto, com as relações cotidianas que envolvem o habitante e suas práticas, a sua vivência diária, os vários usos do espaço, isto é, a existência dos seres humanos, estes sentindo, pensando, apropriando-se e vivendo o espaço através do corpo e das atividades decorrentes dos saberes e fazeres. O bairro, a comunidade, o "pedaço", são exemplos de lugares.

O agroturismo, uma modalidade de turismo no espaço rural, apresenta-se como um complemento econômico da família não excluindo as práticas agrícolas tradicionais, que permanecem como a principal fonte de renda. É de vital importância que as práticas agrícolas 
não sejam interferidas já que este é um dos fatores que atrai o fluxo turístico para o local. $\mathrm{O}$ agroturismo praticado nos modos atuais é caracterizado pela grande importância da família do agricultor para que se realize, afinal são estes os atores que estão presentes nesta atividade comandando todas as etapas, desde a produção agrícola até a venda dos produtos destinados aos turistas. Agroturismo é definido por Portuguez (1999, p. 77) como: "a modalidade de turismo no espaço rural praticada dentro das propriedades, de modo que o turista e/ou excursionista entra, mesmo que por curto período de tempo, em contato com a atmosfera da vida na fazenda, integrando-se de alguma forma aos hábitos locais".

Uma característica importante do agroturismo é a possibilidade de convivência na propriedade (fazenda, sítio, chácara, etc.), mesmo que por pouco tempo entre o agricultor e sua família e o turista, o qual partilha com o visitante o dia-a-dia do lugar, das atividades produtivas praticadas no estabelecimento, etc., que são os próprios atrativos.

A busca por experimentar formas mais tradicionais de vida, que se oponham a forma de viver do meio urbano, onde o grau de stress é elevado, a rotina é acelerada e maçante, atraí muito os turistas que procuram uma aproximação com a natureza buscando formas de vida mais leves. Isto é conseguido através do tempo mais lento do espaço rural ainda pautado em alguns aspectos no tempo da natureza. O que pode ser visto durante sua estadia inserida na rotina da propriedade, pelas práticas diárias dos moradores, na fabricação dos alimentos como queijos, pães e doces e a lida na roça, por exemplo.

O apelo cultural local também é muito importante no agroturismo já que tais particularidades despertam o interesse do turista e imprimem um caráter único ao espaço. $\mathrm{O}$ individuo que busca tal forma de turismo procura formas diferenciadas de gastar seu tempo de lazer, portanto a identidade da propriedade deve ser preservada. Alguns fatores são relevantes: a cultura étnica da família e do local, a arquitetura das edificações, a culinária tradicional e o tipo de atividade produtiva. Portanto é importante promover o convívio dos visitantes com costumes e hábitos diferentes de sua vivencia urbana, pois além de ser um diferencial ainda ajuda a preservar e reavivar os costumes culturais locais.

Um aspecto muito interessante desta modalidade de turismo é que dentre as novas atividades que estão sendo desenvolvidas no campo, esta ajuda a manter a identidade rural dos moradores desse lugar. A preocupação com identidade ocorre em meio à inserção de atividades que não estão ligadas ao setor agrícola e isso tem gerado preocupação quanto à perda da identidade rural já que a cultura agrícola tem dividido e em alguns casos até perdido espaço para outras culturas (Haesbaert, 2007). 
Nesse sentido, percebe-se que o agroturismo além de contribuir para melhorar a renda das famílias, ajuda no aumento do interesse de familiares, principalmente os mais jovens, em se fixar no campo. Soma-se também o fato de muitas atividades agroturísticas serem muito importante para a conservação do patrimônio cultural desses locais.

\section{CULTURA E AGROTURISMO EM VENDA NOVA DO IMIGRANTE (ES)}

O agroturismo no município de Venda Nova do Imigrante vem de encontro com as expectativas do turista que vai em busca de uma realidade que se distancia do cotidiano na cidade. Assim, o modo de vida rural, a cultura local, as tradições e identidade dos habitantes, juntamente com os produtos oferecidos aos turistas são os grandes atrativos dessa modalidade de turismo.

O turismo, assim como as demais práticas realizadas pelos homens, se dá no espaço. Desta forma, quando se desloca de sua residência o turista busca conhecer novos espaços, se propõe a entrar em contato com o novo, o diferente e descobrir o que ele tem a oferecer. "Os lugares são impregnados de cultura, carregados de história, de tradições são patrimônios naturais e culturais com forte identidade e constituem as bases para o desenvolvimento do turismo." Coriolano e Silva (2005). São essas particularidades presentes nos lugares, suas identidades, cultura e especificidades que despertam o interesse na realização do turismo. " $\mathrm{O}$ turismo é uma invenção cultural direcionada àqueles que buscam o inédito, o desconhecido, o exótico e, sobretudo o contato com a natureza e manifestações culturais." Coriolano e Martins (2007).

O agroturismo elevou a autoestima dessa população e possibilitou uma compreensão pelo próprio agricultor de que seu modo de vida é valorizado por outras pessoas justamente pelos elementos que são considerados tradicionais e que são desvalorizados pelo discurso da sociedade moderna. "Vive-se um tempo em que as sociedades perdem cada vez mais os tradicionais costumes, velhos hábitos, gêneros de vida, profissões e muitos paradigmas são substituídos." Coriolano e Martins (2007). Talvez por isso mesmo formas de turismo como o agroturismo que remonta a maneiras de vida tradicionais e hábitos e costumes dos antepassados esteja tão em alta e alcançando tanto êxito

A cidade de Venda Nova do Imigrante fica localizada a $103 \mathrm{~km}$ da capital, Vitória. Pode ser alcançada tanto pela BR-262, quanto pela BR-101. Está localizada na Região Sudoeste 
Serrana do Espírito Santo, juntamente com os municípios de Afonso Cláudio, Brejetuba, Conceição do Castelo, Domingos Martins, Laranja da Terra e Marechal Floriano.

Figura 1: Mapa de Venda Nova do Imigrante-ES

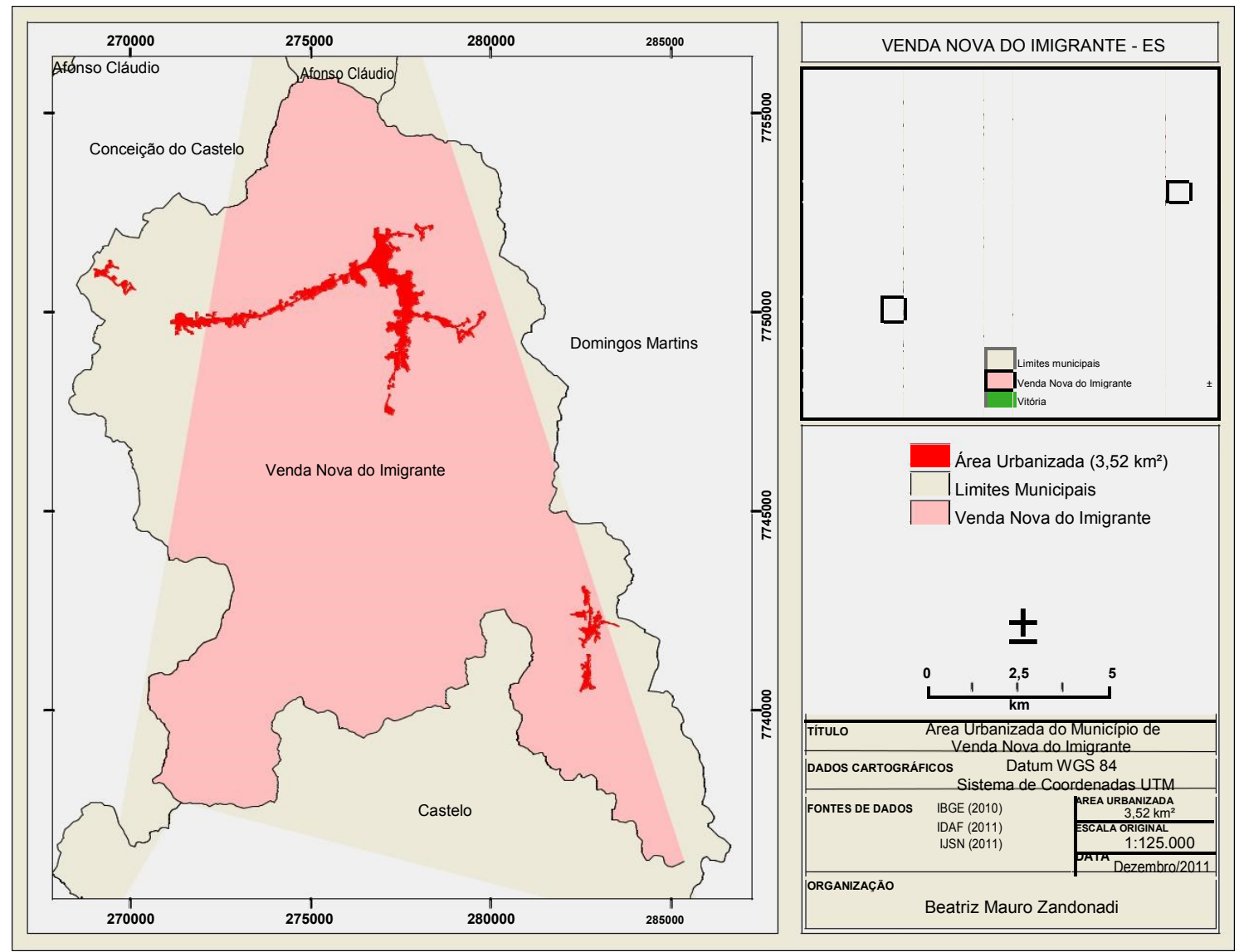

Fonte: elaboração pelas autoras (2015)

Essa região conta com uma população total de 132.069 habitantes dos quais 20.447 são de Venda Nova do Imigrante. Foi emancipado em maio de 1988. No final do século XIX (1891), a localidade começou a receber imigrantes italianos. Logo no início começaram a praticar a agricultura, atividade que já desenvolviam em seu país de origem. O que revela que o município tem uma origem agrícola, conservando essa vocação até os dias atuais.

No entanto ao longo do tempo, sabemos que o setor agrícola passou e vem passando por sucessivas crises, devido à desvalorização da atividade, mecanização no setor, variação econômica, entre outros fatores. O meio rural como um todo passou a abrigar novas atividades que não só as agrícolas como uma estratégia para driblar as dificuldades pelas quais estava passando (Queiroz, 2012). Setores como o da indústria e da prestação de serviços começam a ser desenvolvidos neste ambiente.

Foi nesse contexto que o agroturismo entrou em cena no meio rural de Venda Nova do Imigrante, como uma forma de diversificar a fonte de renda, manter a população no campo e 
superar os problemas pelos quais os agricultores estavam passando, impulsionando uma nova dinâmica nesse espaço.

O município é cada vez mais conhecido pelos seus atrativos à prática do agroturismo, cuja sede ostenta com muito orgulho título de capital nacional do agroturismo. As novas atividades dessa modalidade de turismo já contam com mais de 20 (vinte) anos de consolidação no município, envolvendo inúmeras propriedades. Mas quais serão os fatores, os elementos, os predicados, os quais contribuem para que a atividade tenha se desenvolvido e ganho tanto destaque nesse município?

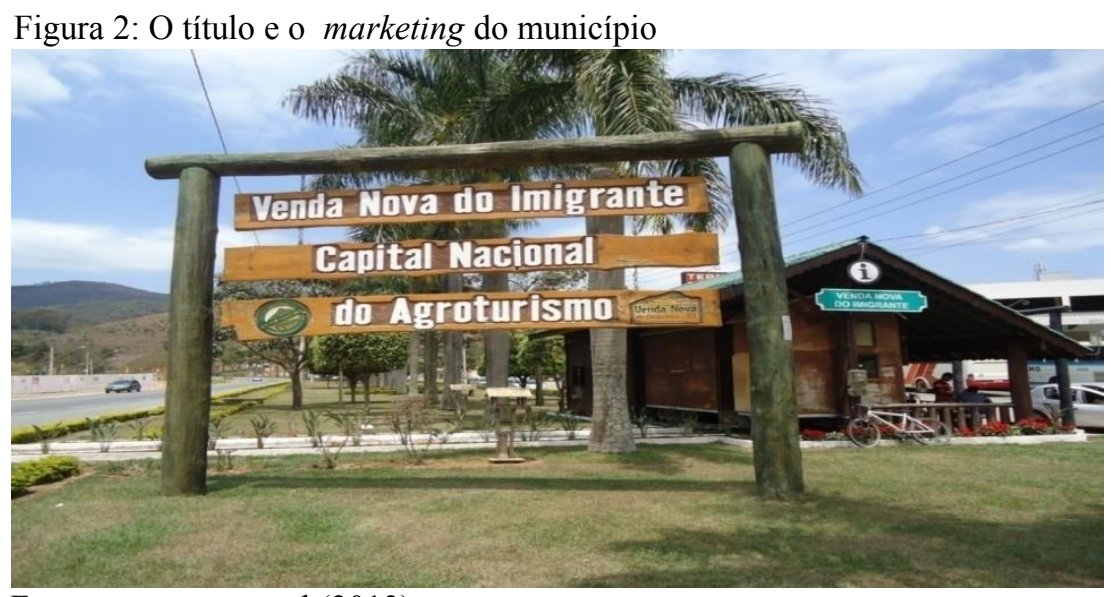

Fonte: acervo pessoal (2013).

A atividade turística no estado do Espírito Santo sempre esteve muito vinculada ao seu litoral, devido à presença de belas praias. O turismo nas áreas litorâneas sempre foi fortemente incentivado pelo governo uma vez que esta prática gera uma receita expressiva para o estado. Visando expandir o circuito econômico do turismo para outras áreas o governo passou a incentivar novos destinos turísticos dentro do estado, inicialmente o Agroturismo na região Serrana Central e o turismo ambiental em torno da Serra do Caparaó.

[...] no Espírito Santo o agroturismo foi eleito como uma das principais atividades a serem fomentadas pelo governo estadual, como oportunidade de promoção do desenvolvimento do campo, não para substituir as atividades agro-silvo-pastoris tradicionais, mas para possibilitar a multifuncionalização das propriedades e como alternativa de geração de renda e ocupação para a população da chamada região serrana central (Portuguez, 1999, p.1).

Os municípios compreendidos pela então chamada Região Serrana-Central do Espírito Santo são: Venda Nova do Imigrante, Castelo, Conceição do Castelo, Domingos Martins, Afonso Cláudio, Santa Leopoldina, Marechal Floriano, Santa Maria de Jetibá, Santa Teresa, Viana e Vargem Alta. Ao longo do tempo, outros municípios também passaram a praticar o 
Agroturismo, mas não foram inseridos oficialmente no programa inicial do Governo do Estado que incentivava a atividade. O Programa Nacional de Municipalização do Turismo PNMT, também deu um grande impulso à prática do Agroturismo. É o caso de outro município da região serrana do estado - Domingos Martins -, o qual vem dinamizando a economia rural com estas práticas (Guaitolini, 2015).

Contudo, o governo do estado, buscando expandir ainda mais as atividades turísticas, e seguindo a tendência nacional, fez a regionalização do seu território turístico. Por meio da participação no Programa de Regionalização do Turismo - Roteiros do Brasil realizou a organização territorial e a definição dos roteiros que serão explorados, criando oito rotas turísticas, que visam abarcar as belezas do estado e dinamizar todas as regiões.

Mas a história do agroturismo no Espírito Santo tem sua semente no início dos anos 1980 com a família Carnielli, proprietária de uma fazenda no município. Eles estavam diante de dois dilemas: ultrapassar a dependência da monocultura do café, cultura muito vulnerável às oscilações do mercado; e conseguir manter os membros da família e os trabalhadores na propriedade, porém com melhores condições de vida. Como ocorre com novas atividades, no início, a família encontrou dificuldades de adaptação, mas aos poucos foram vencendo os problemas. O aumento na produção de leite e a transformação de toda essa matéria prima para não perdê-la representou um desafio. Iniciaram assim a produção de variados tipos de queijo. Os animais, e os queijos chamaram a atenção dos vizinhos e amigos que iam até a fazenda comprar diversos produtos. Assim, sem que este fosse o intuito inicial, tornou-se um atrativo. Os proprietários perceberam então que esta prática poderia se tornar uma alternativa na geração de renda. Hoje, as gôndolas de supermercados no estado exibem diversos produtos com a marca da família, além da construção de pequenas lojas na região serrana.

A família identificou que a maior parte dos visitantes que apareciam em sua propriedade ficava hospedada em hotéis da região ou estavam a passeio na casa de amigos e parentes. Foi quando, em 1992, Leandro Carnielli, membro da família, e na ocasião secretário do Movimento Educacional e Promocional do Espírito Santo, participou do Congresso Internacional das Famílias Agrícolas na Espanha, juntamente com a delegação capixaba composta pelo o vice-governador e Secretário da Agricultura, Adelson Salvador, o jornalista Ronald Mansur, a pedagoga Eliane Statuffer de Andrade Mansur e o Secretário Executivo do Movimento Educacional e Promocional do Espírito Santo (Mepes), João Batista Martins. Após esse congresso eles foram visitar um projeto sobre o Agroturismo na Itália, e durante esta visita a Azienda Agroturística Mondragon de propriedade de Roberto e Tina Tessari, a ideia do Agroturismo em Venda Nova do Imigrante começou a ser gerada. 
$\mathrm{Na}$ ocasião, Carnielli observou uma grande semelhança entre o que ocorria na fazenda de sua família e na Azienda Agroturística, na Itália. Leandro, então, volta à Venda Nova do Imigrante cheio de idéias para ampliar o trabalho na região. Nasce, então, o primeiro ímpeto da atividade no município. Todavia, o agroturismo só se consolida como projeto a partir de 1993, com a criação da "Agrotur" (Centro de Desenvolvimento do Agroturismo), até então com esse significado, esse centro possuía uma representação jurídica, sendo uma maneira de agrupar os interessados em participar da atividade.

Durante as reuniões eles realizavam discussões sobre organização, planejamento e construções de táticas de crescimento. Uma importante estratégia de divulgação foi a proposta do Alpes Hotel, hotel fundando no início da década de 1990 no município, de levar os hóspedes até as propriedades que desenvolviam o agroturismo, tal estratégia gerou um aumento significativo no número de visitas às fazendas.

Como vimos desde o seu surgimento o agroturismo vem crescendo e ganhando proporções cada vez maiores no município, cidade considerada a pioneira nesta prática no estado do Espírito Santo, e referência quando o assunto é o desenvolvimento e consolidação desta forma de turismo. Desde o nascimento da idéia da atividade, as parcerias, e as ações para o desenvolvimento do agroturismo tem progredido de forma expressiva.

O fluxo de turistas tem crescido; muitos municípios vizinhos se espelham e também passou a desenvolver a atividade, a mídia tem dado bastante veiculação e destaque ao município seja em revistas, matérias em jornais impressos, meios eletrônicos especializados em turismo, programas de televisão (Guaitolini, 2015). Além do apoio do Governo do Estado. É no âmbito desse percurso histórico que Venda Nova do Imigrante passou a ficar, cada dia mais conhecida pela prática dessa modalidade turística, sobressaindo uma economia local que cresce a cada dia.

Segundo dados do IBGE (2010), A Região Sudoeste Serrana do Espírito Santo, possuía em 2010, mais homens que mulheres, os primeiros representavam $50,77 \%$ da população, e as mulheres $49,23 \%$. Da população residente por cor ou raça, a maior parte da população $60,65 \%$ se declarou branca. O que pode ser explicado por grande parte dos municípios desta região ter sido colonizado por imigrantes de origem italiana ou alemã, gerando uma população que, ainda em grande parte, é descendente desses imigrantes, conservando características herdadas, seja na tradição das atividades agrícolas, que predominam nesses municípios, nos hábitos e costumes, o que é um diferencial da região e um grande atrativo para o turismo (Marques \& Marques, 2013). A maior parte da população 
dessa região ainda é rural representando $55,58 \%$ do total, sendo os $44,42 \%$ restantes urbana. O que mais uma vez favorece a prática do agroturismo que privilegia o rural e seus habitantes.

Além das características já mencionadas, podem-se elencar alguns elementos que contribuem para o sucesso do agroturismo em Venda Nova do Imigrante, tais como a facilidade de acesso, a sua localização na Região Sudoeste Serrana do estado do Espírito Santo, a infraestrutura urbana, o clima agradável com o predomínio de temperaturas amenas, chamado popularmente de "clima das montanhas". Suas belezas e paisagens naturais, com áreas ainda bem preservadas, uma vez que o município tem relevo bastante acidentado com muitos morros e serras.

Figura 3: Panorama da sede do município de Venda Nova do Imigrante, cortada pela BR 262

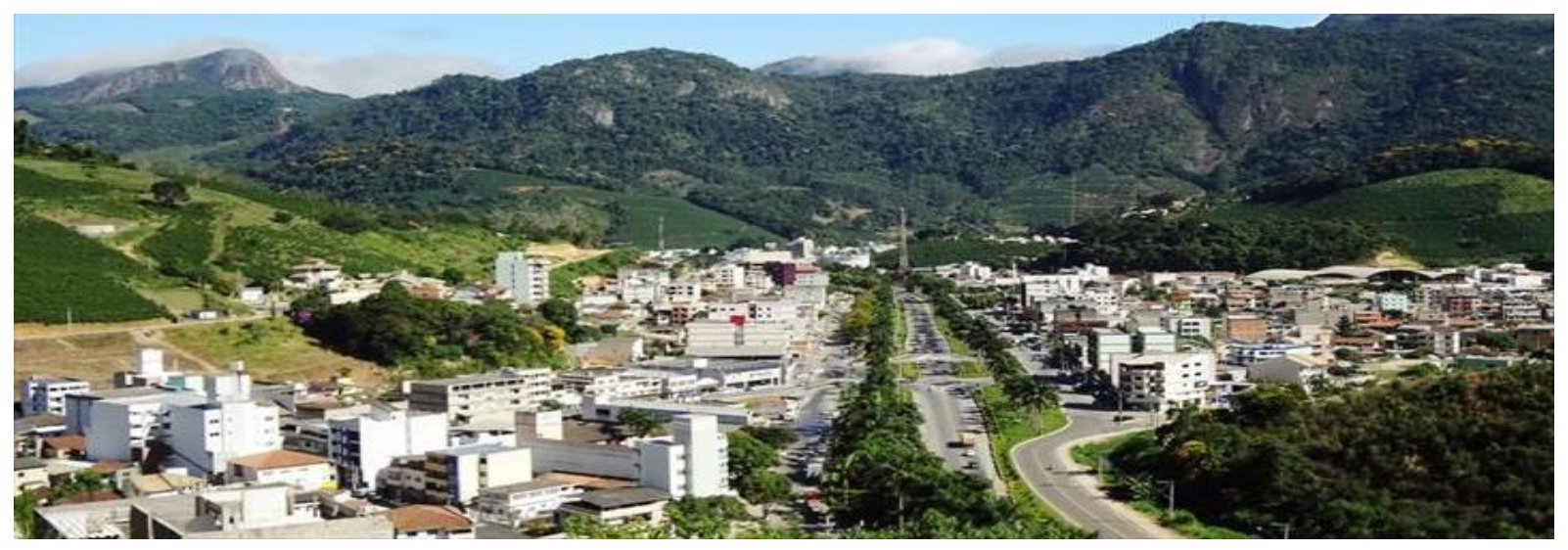

Fonte: Câmara municipal de Venda Nova do Imigrante (2014).

O fato de ter sido colonizada por imigrantes italianos e possuir a história que estamos descrevendo e analisando, mais uma vez, contribui para o desenvolvimento do agroturismo. Esses imigrantes trouxeram e imprimiram suas características culturais típicas, que hoje são um diferencial, por terem sido preservadas pelos seus descendentes. Os moradores ainda preservam traços culinários como os pratos típicos, os quitutes, que aprenderam com os antepassados, as danças, as músicas, os jogos que ainda são lembrados nas datas festivas no município. Tudo isso desperta o interesse dos turistas que buscam conhecer um pouco mais esse local e sua população de hábitos culturais diferentes.

A cultura pode ser utilizada para falar de um conjunto de práticas, valores e hábitos de uma população, diz Gomes (1999). A cultura em Venda Nova do Imigrante passou a ter mais destaque após o início da prática do agroturismo, principalmente em função do envolvimento dos produtores rurais que perceberam o potencial existente nas suas propriedades. Os turistas vêm atrás de conhecer essas particularidades do local, que agora voltam a ser valorizadas, recuperas e preservadas com mais empenho e orgulho. Os hábitos, as tradições e os costumes 
dos mais velhos estão mais vivos do que nunca. As questões culturais suas tradições e modo de vida passaram a ser mais conservados, pois esse é um fator que atraí os turistas. Eles querem conhecer as minúcias, o cotidiano de comunidades com hábitos culturais distintos dos seus. Assim, as festas, a culinária, as músicas, danças e tudo mais que diz respeito à herança cultural dos antepassados italianos são agora explorados, através de festas, comemorações locais que atraem turistas para o município (ver figuras 4 e 5).

Figuras 4 e 5: Apresentação de dança típica durante a festa da polenta. O tombo da polenta
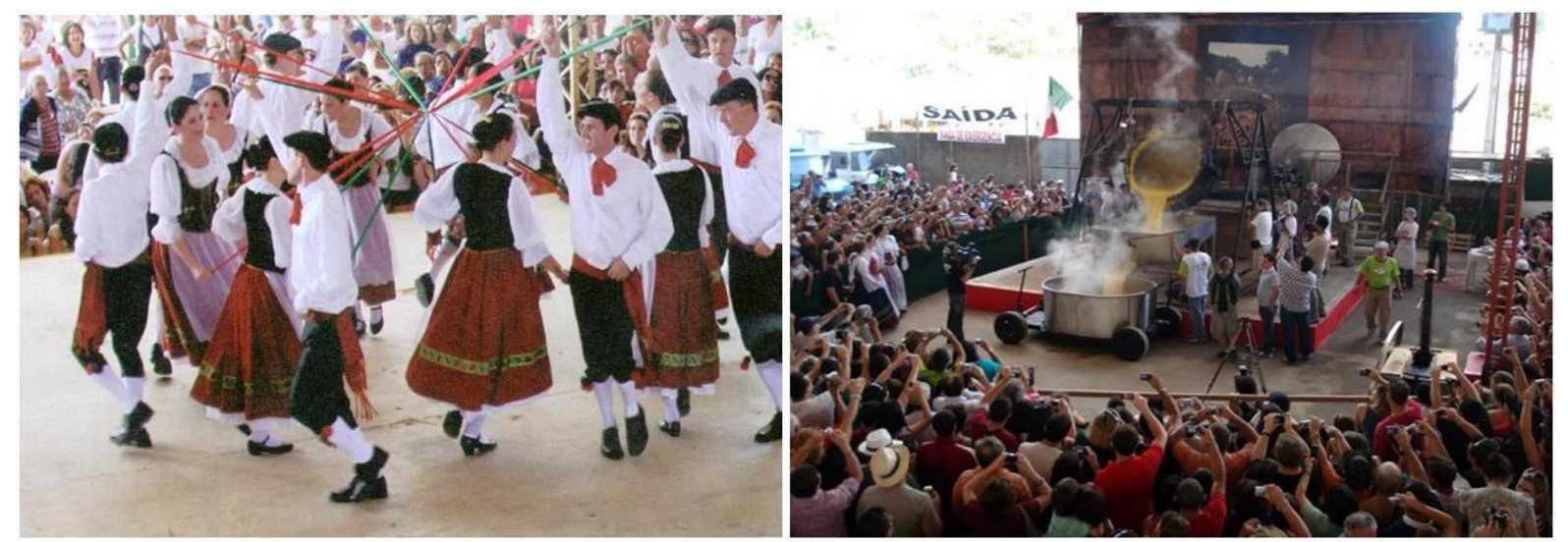

Fonte: acervo da Associação de Agroturismo do Espírito Santo [Agrotur] (2014)

As tradições trazidas pelos imigrantes de sua terra natal, como músicas, jogos, comidas, danças, técnicas de produção, instrumentos, etc., são passados de geração em geração, e por isso, hoje, compõem mais do que nunca a identidade do povo Vendanovense. Haesbaert $(1999 ; 2007)$ discute isso quando diz que determinados grupos de migrantes podem não apenas entrecruzar sua identidade no confronto com outras culturas, mas também levar sua territorialidade consigo, tentando reproduzi-la nas áreas para onde se dirigem; mantendo estreitos vínculos de ordem cultural com seu lugar de origem. Foi isto que esses imigrantes fizeram no município, mas que haviam, em parte, deixado de lado. Agora reafirmam sua territorialidade, valorizam a memória e reproduzem traços da cultura dos antepassados, mesmo que nada não passe apenas de simulacros mostrando um pedacinho da Itália no estado.

\subsection{ANÁLISES DOS RESULTADOS}

Para entender e analisar o agroturismo praticado no município de Venda Nova do Imigrante fez-se importante um estudo sobre as propriedades e as atividades agroturísticas desenvolvidas, bem como alguns aspectos relacionados à dinâmica do agroturismo local. As 
propriedades pesquisadas nos deram aporte para entender a dinâmica e as tendências do município, especialmente no que tange aos produtos voltados o público turista.

O grupo pesquisado - uma amostragem - engloba 17 propriedades, das 23 contidas no panfleto turístico oficial do município em 2013, ou seja, 69,56\% do total. Limitamos-nos a essas propriedades por serem as que possuem uma produção de caráter familiar, e por estarem mais de acordo com as práticas preconizadas pelo agroturismo.

As propriedades que analisadas foram as seguintes: Fazenda Carnielli; Sítio Retiro do Ipê; Família Busato; Pousada Bela Aurora; Sítio Morango Gagno; Sítio Guaçú-Virá; Cláudia Artesanato; Tia Cila; Família Lorenção; Sítio e Adega Tonole; Casa das Orquídeas; Orquidário Caliman; Sítio Raízes da Terra; Altoé da Montanha; Sítio Ambrosim, Sítio Brioschi e Fazenda Saúde.

Entre o grupo pesquisado, o número de mulheres envolvidas na produção salta aos olhos. Grande parte das pessoas envolvidas diretamente nos processos produtivos e na venda dos produtos são do sexo feminino, reafirmando a importância e o papel da mulher no agroturismo local. Aliás, esse é um fator que não poderia deixar de ser abordado: a mulher e seu papel nas atividades agroturísticas. São as responsáveis diretas em produzir os quitutes, os artesanatos, por dar aquele ar aconchegante e de cara de casa de avó que as propriedades têm, são as responsáveis por receber e lidar diretamente com o turista, são elas que gerenciam todos os aspectos ligados às atividades, participam das reuniões na associação, etc.

Além do café, os demais produtos são: hortaliças, na propriedade da Pousada Bela Aurora, Morango, na propriedade Morango Gagno, tomate e banana, no projeto Guaçú-Virá, Orquídeas em duas propriedades, no Orquidário Caliman e na Casa das Orquídeas, uva na Família Tonoli, e milho e feijão na propriedade Fazenda Saúde. Apenas na propriedade da Tia Cila, ela alegou não manter nenhum tipo de produção agrícola. A família resolveu trabalhar apenas com quitutes para os turistas, como geleias, biscoitos, bolos, pães, queijos, embutidos e doces.

Em seis propriedades pesquisadas não existe nenhum produto agropecuário de grande monta, a exemplo do café. Trata-se de produtores voltados para um público específico. A Casa das Orquídeas e Orquidário Caliman, produzem apenas flores, que vendem no local, em feiras e abastecem floriculturas em algumas cidades; o Sítio Guaçú-Virá produz apenas bananas e tomate na forma de doces, molhos prontos e compotas; a Tia Cila se especializou em fabricação de doces, pães, biscoitos atendendo em loja fixa (ver figuras 6 e 7). 
Figuras 6 e 7: loja com produtos da Família Carnielli; decoração interior com objetos antigos de família
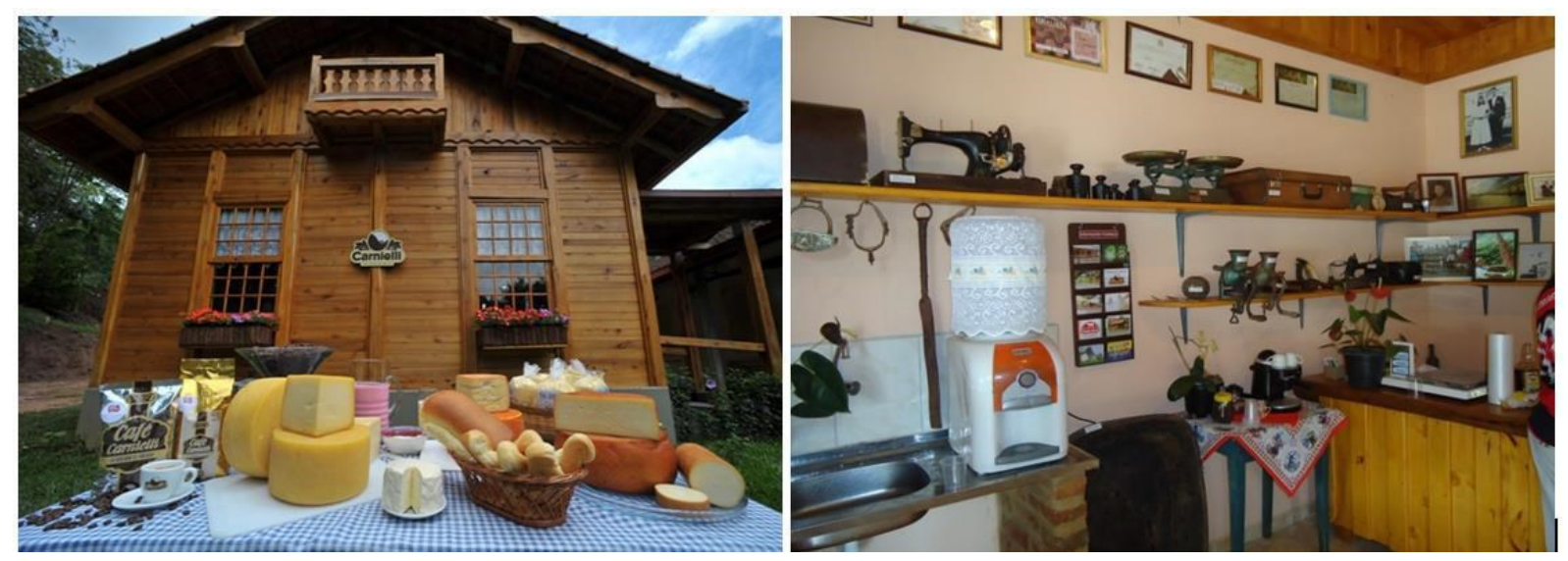

Fonte: acervo do Agrotur (2014)

Dentre os produtos agropecuários complementares existentes nas propriedades, os que mais se destacaram foram: milho, feijão e abacate, que apareceram em cinco propriedades. $\mathrm{O}$ milho e o feijão apareceram nas propriedades das famílias Busato, Retiro do Ipê, Artesanto da Cláudia, Família Lorenção e Morango Gagno. O abacate, a manga, a mexerica, além de hortaliças, são também considerados produtos complementares nas propriedades das famílias Busato, Retiro do Ipê, Altoé da Montanha, Sítio Raízes da Terra e Sítio Adega Tonole. O palmito pupunha apareceu em uma propriedade, a da família, Carnielli. Outro produto também complementar dessa última propriedade é a madeira (eucalipto), que também está presente na propriedade Retiro do Ipê, além do pinus voltado para a fabricação de móveis.

Quatro famílias disseram também manter a produção de frutas, produção de doces, pães e vinhos em suas propriedades, são elas: Alto é da montanha, Raízes da Terra, Sítio Adega Tonole e Pousada Bela Aurora.

Três famílias também preservam a produção de hortaliças: a fazenda Saúde, que possui a produção dessas hortaliças para a utilização no restaurante que eles mantêm na propriedade, a Família Lorenção que produz brócolis e tomate italiano, além de frutas e o sítio Gagno, que também mantém produção de hortaliças e frutas, sobretudo o morando, vendido também em diversas feiras.

O café apareceu como um produto complementar na propriedade da família Tonole. Onde o produto principal é a uva e seus derivados. O pesque-pague Ambrosim citou como produto agrícola complementar ao lazer do turista, um pouco de pasto visando a produção de leite e derivados. Na Pousada Bela Aurora, a família também disse manter animais na propriedade para a produção de leite e derivados, além da fabricação de pães, doces, vinhos, 
etc., os quais abastecem os hóspedes e negociam parte da produção em feiras na grande Vitória.

Preocupamo-nos em entender como esses proprietários exploram o Agroturismo dentro de suas propriedades. Descobrimos que todos exploram de alguma forma os denominados atrativos culturais materiais e imateriais, como as paisagens, a história das famílias, os seus traços históricos e culturais. Esse é o caso da Casa das Orquídeas, que apenas vende plantas e flores; Artesanato da Cláudia, que recebe na loja e vende diversos tipos de artesanato; Tia Cila, que também recebe turistas na loja e vende seus pães, bolos, massas e biscoitos; Orquidário Caliman, que recebe turistas e estudiosos de orquídeas e bromélias, onde essas plantas podem ser admiradas e em alguns casos elas podem ser adquiridas, e o Sítio Raízes da Terra, que vende seus quitutes, como geleias, biscoitos, antepastos entre outros.

Alguns entrevistados exploram outros aspectos da propriedade de forma mais efetiva. A maior parte explora as amenidades da propriedade, os campos, cachoeiras, rios e lagos, as lavouras, plantações, criações (de vacas, galinhas, porcos, carneiros e outros animais domésticos) e outras particularidades do campo, que muito interessam aos turistas. Assim, no Sítio do Morango Gagno os proprietários levam o turista para ver tudo o que ele quiser na propriedade, principalmente as roças de fruta como a de morango e a de uvas. Na Fazenda Saúde eles têm como outros atrativos, o pesque-pague, pedalinhos, restaurante, aves, além das amenidades da propriedade, como ar puro e belas paisagens.

A diversificação e a manutenção de produtos secundários dentro da maioria dessas propriedades é uma maneira de essas famílias diversificarem seus investimentos e sua renda, além de aproveitar os espaços e potencialidades existentes na propriedade até então não exploradas. Isto, de fato, vem contribuindo muito para o desenvolvimento do agroturismo, posto que, em vários casos, os produtores podem usar os complementos na produção principal para serem vendidos in natura para os turistas, aumentando suas opções de venda. Acrescente-se a isso o quanto os produtos se tornam um atrativo aos turistas, que gostam de ver as plantações, e quando possível, entrar em contato direto na colheita de hortaliças, verduras, frutas, café, morango, na produção de vinhos e queijos, os animais, etc., sendo a visita guiada mais uma atividade que agrega valor (ver figura 8). 
Figura 8: típica paisagem rural do circuito de agroturismo

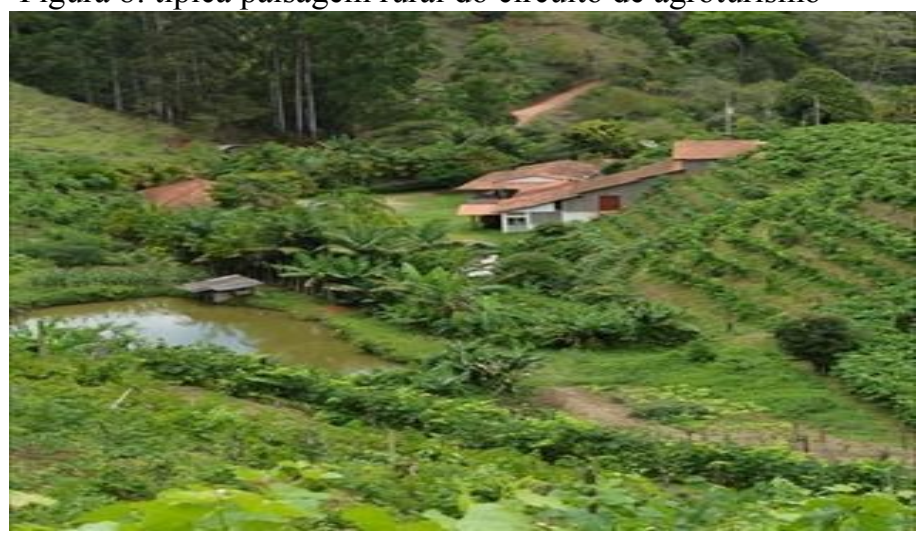

Fonte: acervo das autoras (2014).

Por fim, além das visitas às áreas produtoras, os moradores se organizam na tarefa de permitir que o turista possa visitar suas residências, posto que foi feito um esforço no sentido de recuperar as casas, arrumar o entorno delas e valorizar a decoração das mesmas, dandolhes um ar mais rústico e dotadas de mais elementos/objetos culturais herdados de familiares mais velhos, como os avós. Assim, o velho mobiliário desprezado é reformado, assim como instrumentos usados na produção, ferramentas, etc., de forma a representar melhor "o diferente", "o exótico", "o tradicional", como atrativos ao visitante/turista.

Tabela 1 - Sistematização de Dados Coletados em Trabalho de Campo

\begin{tabular}{|c|c|c|}
\hline $\begin{array}{l}\text { PROPRIEDADES } \\
\text { (17 NO TOTAL) }\end{array}$ & $\begin{array}{l}\text { TRANSFORMAÇÕES } \\
\text { IMPLEMENTADAS VISANDO O } \\
\text { AGROTURISMO }\end{array}$ & $\begin{array}{l}\text { ATRATIVOS } \\
\text { AGROTURÍSTICOS }\end{array}$ \\
\hline \begin{tabular}{ll}
\multicolumn{3}{l}{ Fazenda Carnielli; Sítio Retiro do } \\
Ipê; Família Busato; Pousada Bela \\
Aurora; Sítio Morango & Gagno; \\
Sítio Guaçú-Virá; & Cláudia \\
Artesanato; Tia Cila; & Família \\
Lorenção; Sítio e Adega Tonole; \\
Casa das Orquídeas; Orquidário \\
Caliman; Sítio Raízes da & Terra; \\
Altoé da Montanha; & Sítio \\
Ambrosim, Fazenda Saúde e Sítio \\
Brioschi.
\end{tabular} & $\begin{array}{l}\text { Diversificação da produção; } \\
\text { Cursos de capacitação e orientação } \\
\text { para os negócios;Maior } \\
\text { envolvimento da r famíliana } \\
\text { produção;Estratégias de marketing; } \\
\text { Construção de estruturas, reformas } \\
\text { e adaptações físicas na propriedade; } \\
\text { Modernização do setor de vendas; } \\
\text { Modernização das áreas de plantio } \\
\text { (hortas e pomares);Modernização } \\
\text { e/ou criação de áreas de lazer; } \\
\text { Reflorestamento/jardinagem. }\end{array}$ & $\begin{array}{l}\text { Produtos alimentícios naturais } \\
\text { orgânicos in natura; } \\
\text { Artesanatos; } \\
\text { Vinhos e queijos; } \\
\text { Cafés especiais; } \\
\text { Frutas e legumes processados; } \\
\text { Grãos selecionados (milho, café e } \\
\text { feijão); } \\
\text { Farinhas especiais; } \\
\text { Plantas e flores; } \\
\text { Carnes orgânicas (frango, carneiro, } \\
\text { porco); } \\
\text { Pães, doces e biscoitos. } \\
\text { Hotéis, pousadas e lazer. }\end{array}$ \\
\hline
\end{tabular}

Fonte: dados coletados na pesquisa empírica (2014; 2015). Org. as autoras, 2015. 


\section{CONSIDERAÇÕES FINAIS}

Ressaltamos vários pontos positivos nas atividades voltadas para o agroturismo, mostrando como esta modalidade de turismo pode possibilitar uma nova dinâmica na zona rural possibilitando a preservação da identidade rural, da cultura, pois ajuda a preservar legados deixados pelos imigrantes; possibilitando a aproximação e intercâmbio entre população rural e urbana, além de abrir portas para novas fontes de renda.

No âmbito cultural, algumas transformações chamam a atenção no caso de Venda Nova do Imigrante. Primeiramente, constatamos que a atividade contribuiu na mudança da forma de ver o próprio lugar. Os moradores que estão ligados ao agroturismo, começaram a valorizar mais seu espaço após o contato com os turistas, assim como também muitos citaram o fato de se sentirem mais valorizados. Muitos produtores envolvidos com novas atividades demonstram ser negativa a falta da rotina, e a perda do convívio dos mesmos no seio da comunidade local, isto é, durante finais de semana, durante festas e horários não programados é preciso recepcionar os turistas. Por outro, houve um ganho com uma maior interação com os "de fora".

De exposto, vimos que o agroturismo se mostra uma alternativa importante para a manutenção do homem no campo, posto que as famílias tem mais uma opção econômica de permanecer no espaço rural, mantendo sua ligação com a terra e com as práticas agrícolas. É uma maneira de diversificar a renda, tornando menos frágil o produtor à mercê apenas das oscilações do mercado agrícola para produtos tradicionais. Ou seja, são novas atividades que surgem como complemento da renda, ou ainda como vimos uma fonte principal que garante o sustento desde que haja orientações, estudos, etc., acerca do mercado consumidor e da dinâmica que envolve o turismo.

No caso de Venda Nova do Imigrante, o agroturismo se mostra eficiente para reforçar a autoestima e preservar a identidade dos habitantes do meio rural, já que promove a valorização de um modo de vida que o visitante/turista quer ver, conhecer e consumir o que há de mais autêntico na localidade. No entanto, é preciso cuidado no que tange à transformação de uma dinâmica agrícola tradicional em função de "vocações" que emergem de tempos em tempos, assim como com a invenção de tradições e costumes enquanto forma de incorporar uma tendência econômica que vem mostrando sucesso no mercado atual.

Constata-se que o agroturismo tem contribuído para manter vivas as tradições e a história local. Todavia, como já mencionado, há que se tomar muito cuidado com essa 
estratégia, pois as tradições e identidades se fazem juntando passado e presente. Deve-se fazer uso das raízes culturais, lembrando que elas vão se modificando e interagindo com o presente. É importante manter as raízes culturais, mas não apenas para que elas se tornem atrativos para o turismo, mas sim porque fazem sentido e parte da identidade dos moradores do lugar.

\section{REFERÊNCIAS}

Associação de Agroturismo do Espírito Santo. (2014). Encarte para distribuição pública.

Associação de Agroturismo do Espírito Santo. (2014). Material de propaganda. Vitória, ES.

Benevides, I. P. (1997). "Para uma agenda de discussão do turismo como fator de desenvolvimento local". In: A.B., Rodrigues (Org.). Turismo e Desenvolvimento Local. (pp.23-41) São Paulo: Hucitec.

Câmara Municipal de Venda Nova do Imigrante (2014). Acervo de fotos disponível para reprodução no local.

Cascudo, L. da C. (1973). Civilização e Cultura. (Vol. I). Rio de Janeiro: José Olympio Editora.

Claval, P. (2007). Geografia Cultural. Florianópolis: EDUSC.

Coriolano, L.N.M.T. \& SILVA, S.C.B.M. (2005). Turismo e Geografia: abordagens Críticas. Fortaleza: UCDE.

Coriolano, L.N.M.T \& Martins, J.C. de O. (2007). O turismo na construção das identidades contemporâneas. In: L.N.M.T Coriolano \& F.P., Vasconcelos, (Orgs.). O Turismo e a Relação Sociedade - Natureza: realidades, conflitos e resistências. (pp.227-243) Fortaleza: UECE.

Cosgrove, D. (1998). “A Geografia está em toda parte: cultura e simbolismo nas paisagens humanas”. In: R.L.,Corrêa, \& Z. Rosendahl, (Orgs.). Paisagem, Tempo e Cultura (pp.92122). Rio de Janeiro: Bertrand Brasil.

Costa, B. P. da (2005). As Relações Entre os Conceitos de Território, Identidade e Cultura no Espaço Urbano: por uma abordagem microgeográfica. In: R. L. Corrêa \& Z. Rosendahl, (Orgs.). Geografia: Temas Sobre Cultura e espaço. (pp. 79-114). Rio de Janeiro: Bertrand Brasil.

Gomes, P. C. C.(1999). Cultura ou civilização: a renovação de um importante debate. In:

Z. Rosendahl, \& R.L., Corrêa. Manifestações da cultura no espaço.(pp.99-123). Rio de Janeiro: EdUERJ.

Guaitolini, R. N. (2015). Espaços Pluriativos da Agricultura Familiar em Domingos MartinsES. Dissertação de Mestrado. Universidade Federal do Espírito Santo, Vitória, ES, Brasil.

Haesbaert, R. (1999). Identidades Territoriais. In: R.L.Corrêa \& Z. Rosendahl (Orgs.). 
Manifestações da cultura no espaço.(pp.169-190). Rio de Janeiro: EdUERJ.

Haesbaert, R. (2007). Identidades Territoriais: entre a multiterritorialidade e a reclusão territorial (ou do hibridismo cultural à essencialização das identidades). In: F.G.B. Araújo, \& R.,Haesbaert, (Orgs.). Identidades Territoriais: olhares contemporâneos. (pp.33-57) Rio de Janeiro: Access.

Instituto Brasileiro de Geografia e Estatística. (2010). Censo Demográfico. Recuperado em 05 de dezembro, 2011, de www.ibge.gov.br

Instituto de Defesa Agropecuária e Florestal do Espírito Santo. (2014). Encartes com dados gerais. Vitória: ES.

Instituto Federal de Educação Superior. Campus de Venda Nova do Imigrante (2014). Lista de cursos. Vitória, ES.

Instituto Jones dos Santos Neves-ES. (2014). Prospectos de divulgação pública. Vitória, ES

Marques, R. A. \& Marques, M. L. DE L. (2013). Agroturismo na Região Serrana do Espírito Santo e a Dúvida de Alguns Agricultores: receber turistas e vender seus produtos ou vender apenas fora da propriedade. Anais do Simpósio de Excelência em Gestão de Tecnologia. [SEGET] Vitória, Espirito Santo, Brasil, 10.

Pires, M. J. (2002). Lazer e Turismo Cultural. São Paulo: Manole Editora.

Portuguez, A. P. (1999). Agroturismo e Desenvolvimento Regional. São Paulo: Hucitec.

Queiroz, O. T. M. M. (2012). O Meio Rural e sua Apropriação pelo Turismo. In: A., Portuguez, G., Seabra \& O.T.M.M., Queiroz. Turismo, Espaço e Estratégias de Desenvolvimento Local (pp.45-60). João Pessoa: UFPB.

Rodrigues, A. B. (Org.) (1997). Turismo e Desenvolvimento Local. São Paulo: Hucitec.

Santos, M. (1996). A Natureza do Espaço. Técnica e Tempo. Razão e Emoção. São Paulo: Hucitec.

Secretaria Municipal de Agricultura (2014). Dados gerais de produção agropecuária do Estado do Espírito Santo. Encarte disponível ao público. Vitória, ES

Secretaria de Turismo. Prefeitura Municipal de Venda Nova do Imigrante (2014). Material disponível ao público. Vitória, ES.

Serviço Brasileiro de Apoio as Micro e Pequenas Empresas de Venda Nova do Imigrante (2014). Documentos diversos. Vitória, ES

Thompson, J. B. (1998). Ideologia e Cultura Moderna. Teoria Social Crítica na Era dos Meios de Comunicação de Massa. Petrópolis-RJ: Vozes. 